\title{
O amor no museu: uma experiência de ensino de História com objetos do amor romântico
}

\author{
Love at the museum: an experience of \\ teaching history with objects of romantic love
}

Kênia Sousa Rios*

\section{Resumo}

$\mathrm{O}$ artigo tem a intenção de compartilhar uma experiência de aula de história da Universidade Federal do Ceará, analisada com base na temática do amor romântico. $\mathrm{O}$ assunto colocou a história dos sentimentos como possibilidade de reflexão historiográfica e ao mesmo tempo ajudou a construir uma opção didática para o ensino de história entre alunos da graduação e alunos do ensino médio na forma de uma exposição no Museu Histórico do Ceará, em Fortaleza.

Palavras-chave: ensino de História; objetos; museu; amor.

\section{Abstract}

The article intends to share an experience of history class held at the Federal University of Ceará from the theme of romantic love. The subject placed the history of feelings as the possibility of historical analysis and at the same time has built an educational option for teaching history between graduate students and high school students in the form of an exhibition at the Historical Museum of Ceará, Fortaleza.

Keywords: History teaching; objects; museum; love.

O amor é assunto "na pauta do dia" entre os estudantes de 16 a 20 anos, idade dos alunos da graduação do curso de História da UFC. Assim, podemos dizer que a faixa etária dos envolvidos no exercício facilitou o convencimento de que podíamos refletir sobre o amor, não só na sala de aula, mas também organizando uma exposição no Museu de História da Cidade.

Histórias de amor tornam-se corpo na medida em que dispomos das assim chamadas "provas de amor", entendidas aqui não apenas como os objetos que convencem alguém de que está sendo verdadeiramente amado, mas vestígios que dão materialidade a possíveis narrativas históricas sobre o amor.

Com esse entendimento, eu e os alunos partimos para a grande aventura de tornar possível a reflexão histórica em face dos objetos do amor romântico. Coisas que guardaram a intimidade e a loucura de histórias e enredos pessoais

*Universidade Federal do Ceará (UFC). keniata13@hotmail.com 
mas que passaram a ser compreendidas e lidas na intenção da Oficina Histórica. Desse modo, cada objeto selecionado tinha nome, corpo, cheiro e endereço, ao mesmo tempo em que escapava do íntimo para dar-se ao estudo de estudantes de história. Nessa perspectiva, papéis culturais de homens e mulheres, relações econômicas e familiares, religião, trabalho e sociedade de consumo foram temas que fizemos surgir nas linhas de uma carta de amor.

E foi assim que encontramos nosso primeiro objeto:

\section{A CARTA E A MÁQUiNa DE ESCREVER}

Na manhã de 18 de maio de 1934, o chefe de trem da segunda classe da Estação Ferroviária Luís Felipe toma uma difícil e importante decisão na sua vida: casar-se novamente. A moça era honesta e prendada, e o chefe, por seu turno, sempre andou na linha e tinha como prover o lar. ${ }^{1}$ Do primeiro casamento restou-lhe a saudade e cinco filhos que não conseguia criar sozinho. Mas a partir daquele dia, se tudo desse certo, não estaria mais só. Tudo estava dependendo da mais sagrada das palavras: sim.

Com a decisão tomada, tratou de formalizar o pedido de casamento. As palavras definitivas tinham que chegar à moça de modo especial. Não podiam ser apenas ditas, afinal o candidato ao coração de Carminha era chefe de trem, lidava com equipamentos modernos, engrenagens, velocidade. Em Fortaleza, naqueles tempos, somente pessoas nobres comunicavam-se por meio da escrita e, para o prazer de Carminha, seu pedido de casamento seria datilografado. Quantas pessoas tinham acesso a máquinas de escrever em 1934, em Fortaleza? Quantos sabiam datilografar?

Em pouco tempo estavam casados, e juntos viveram até os últimos dias. Carminha cuidou de seus filhos, que tiveram outros filhos. A moça transformou-se em avó, mas nunca se desfez daquilo que, em meio a tantas quinquilharias acumuladas, parecia ser o mais valioso de todos os objetos da casa.

Os netos sabiam do apego de sua avó à carta, mas talvez não entendessem direito o motivo, diante de uma missiva curta e ainda por cima datilografada. Sem falar, é claro, na falta da assinatura do avô. O certo é que tinha ela lugar especial na casa e, na mesma gaveta, uniu-se a outro importante documento: a carteira de trabalho do chefe de trem da segunda classe. Foram unidos para 
compor uma única e indissolúvel coisa que, afinal, garantiu a união dos dois para todo o sempre.

Passados 70 anos da carta que uniu Carminha ao chefe de trem da segunda classe, os alunos da disciplina Introdução aos Estudos Históricos, ofertada pelo curso de História da UFC, visitaram o Museu do Ceará, e eu, como professora, solicitei que trouxessem para sala de aula objetos domésticos que julgassem dignos de uma exposição num Museu Histórico. Entre revistas antigas, fotos, moedas, discos e roupas estava a Carta. O neto a trouxe à sala alegando que nada na sua casa poderia ser mais importante do que aquele papel. A avó Carminha dedicou excessivo zelo ao objeto durante sua vida. Sem tentar explicar muito, o neto trouxe, dentro do mesmo antigo e cuidado saco plástico, a carteira de trabalho de seu avô. Contou-nos que sempre estiveram juntas e sempre eram exibidas simultaneamente. Ele, portanto, repetia o ritual que tantas vezes presenciou em casa, trazendo para a sala os dois objetos juntos.

Começamos a ler a carta e todos queriam dar uma opinião sobre o momento íntimo de D. Carminha, vivido há 70 anos. Uns se admiraram com a falta de romantismo, outros ignoraram a falta da assinatura, e alguns até implicaram achando que o chefe queria somente uma babá para os filhos órfãos. E foi aí que a ideia da exposição surgiu.

A carta do chefe transformou-se em objeto de museu. Contrariando o que alguns podiam pensar, a missiva só chegou ao museu porque expressava a vida, não só do casal em questão, mas de muitos homens e mulheres que viveram em Fortaleza na década de 1930. As razões do casamento, o valor do trabalho, os papéis masculino e feminino na união conjugal, a escrita e os utensílios da escrita eram temas possíveis de tratar através do objeto guardado durante tanto tempo por D. Carminha. O fato de ela ter guardado o texto já gera reflexão. Quantos de nós atualmente escrevemos cartas? O que mudou nas condições masculina e feminina dentro do casamento? O que permaneceu? Por que não havia romantismo nas palavras do chefe de trem? Por que ele não colocava o amor romântico como elemento da união? Por que causava tanta estranheza, aos alunos, a definição de mulher e de homem proposta pelo chefe em sua carta?

Os alunos mais interessados na coordenação da exposição começaram a organizar sessões de estudo sobre os temas que iam surgindo. Fizemos um bom levantamento bibliográfico para viabilizar o desempenho dessas sessões. 
Certamente as tantas questões suscitadas pela carta não seriam encerradas nesse documento. Era preciso juntar a ele outros objetos que nos ajudassem a entender melhor o amor na cidade de Fortaleza durante o século XX. Fizemos um verdadeiro mutirão dentro do curso de História. Nossa campanha tentou sensibilizar alunos, professores e servidores para o empréstimo de fotos de casamento, cartas de amor, bilhetes, cartões, caixinhas, enfim, tudo o que fosse indício das "histórias de amor" no espaço doméstico. E cada objeto que aparecia era um desafio novo que se abria.

Montamos uma equipe de pesquisa e curadoria para a exposição, e outros alunos se transformaram em importantes colaboradores. Em um mês tínhamos um significativo acervo amoroso que contava histórias de tios, amigos, avós e bisavós por meio de fotos (sobretudo de casamento), cartas, bilhetes, cartões, retratos pintados, álbuns de casamento, objetos que envolviam alunos do curso inteiro. Agregamos objetos pertencentes ao Museu do Ceará, e um grande número de títulos de cordéis com temas românticos foi incorporado ao acervo inicial.

Alguns perguntavam se somente serviriam os objetos de "gente importante”. Quando explicávamos que todos tinham espaço na nossa exposição pois todos eram importantes -, a satisfação era notória. Alguns alunos começaram a convencer pais e parentes da importância histórica daquele bilhetinho, do cartão do dia dos namorados, das fotos. Os parentes ficaram curiosos para saber em que ia dar aquele "fuxico". Foram todos convidados para ver o resultado final no dia da abertura da exposição, cuja data não poderia ser outra senão "o dia dos namorados".

De posse dos objetos emprestados, começamos a pensar nos temas e problemáticas históricas da exposição. Quais seriam os principais recortes temáticos? Como abordá-los historicamente em uma exposição museológica? Os objetos nos sugeriam quais os caminhos possíveis e a bibliografia nos ajudava a percorrê-los.

Finalmente começamos a esboçar o primeiro desenho da exposição a partir de temas: 1. Imagens do amor: fotografia e pintura (retratos de casamento e namoro, álbuns nupciais, máquinas fotográficas, retratos pintados); 2. O amor por escrito (cartas de amor, cartões românticos, máquina de datilografia, canetas, escrivaninha); 3. O amor e a mobília (uma namoradeira do final do século XIX, pertencente ao acervo mobiliário do Museu do Ceará, quadros); 4. 
A devoção do amor (simpatias, versos para Santo Antônio, objetos usados em rituais de simpatia, santo sem cabeça, santo enforcado, velas de todas as cores e formas). O amor em versos (cordéis com temas românticos). O mercado do amor (objetos relacionados ao apelo do comércio no dia dos namorados, incluindo um arsenal de objetos eróticos vendidos em sex shop). Para cada tema discutimos autores que, a partir de suas inflexões históricas, ajudaram a dispor os objetos de modo reflexivo.

Restava selecionar os objetos e iniciar a montagem da exposição. O desafio inicial era excluir o menor número de peças coletadas, afinal, as pessoas fizeram os empréstimos na maior boa vontade. Tratamos de garantir que ninguém fosse preterido, mesmo que não usássemos todos os objetos cedidos por aquela pessoa. Por exemplo, se não usássemos a carta, usaríamos a foto ou o cartão, ou o objeto da simpatia etc. E assim, com a assessoria do diretor do Museu, começamos a montar a exposição.

Concentramo-nos no primeiro módulo, que, aliás, não era o primeiro por acaso. Fomos construindo o percurso da exposição seguindo a quantidade de cada tipo de objeto, e naquele momento já não tínhamos dúvida: rico, pobre ou miserável, todos têm foto de casamento.

\section{O AMOR QUE SE RETRATA}

A fotografia era o principal objeto romântico presente no espaço doméstico. Juntamos um volume espantoso de fotos de casamento. Conseguimos transitar por todo o século XX, já que a mais antiga datava de 1903, e a mais recente, de 2003, com representação de todas as décadas no intervalo dessas datas. Algumas nos chegaram avulsas, mas a maior parte apareceu-nos na sequência tradicional e organizada do álbum nupcial.

Como última etapa da publicidade da união, ${ }^{2}$ o retrato de casamento mostra, em poses repetidas, o modo como os casais apresentam o seu grande dia: a entrada da noiva, os dois no altar, o beijo, o brinde com as taças cruzadas, a noiva na cama com os presentes, o arremesso do buquê, a saída no carro, a entrega da noiva, pelo pai, ao marido.

O clique da fotografia conta de modo parecido as muitas "histórias de amor" ao longo de todo o século XX. Pelo menos no álbum nupcial, os casos 
de amor se eternizarão, intocados e organizados numa sequência que iguala os amantes numa promissora vida a dois.

A marca principal das fotos de casamento é, sem dúvida, o vestido branco da noiva, que, aliás, manteve-se sem grandes alterações na composição imagética da fotografia ao longo dos avanços que os equipamentos fotográficos apresentaram. O branco permaneceu branco na foto colorida ou em preto e branco. Nas mais recentes, apenas o rosto da noiva denuncia o colorido captado pelos progressos da máquina. Tudo indica que nenhum ângulo maculará a imagem da noiva, que para sempre permanecerá um símbolo de pureza.

O branco continua na pauta dos casamentos, não importa o tamanho, as alegorias ou o modelo. As noivas ocidentais, em sua grande maioria, optam pela alvura de suas vestes. Com os apelos da moda, a relação se abre continuamente, já que esta, em certa medida, dialoga com a postura feminina e suas conquistas mais imediatas. E apesar de toda a sacralidade do ritual, a roupa da noiva não deixou de marcar as formas de participação feminina no tempo e no espaço.

Já nas décadas de 1920 e 1930 podemos ver os tornozelos e joelhos em sutis vestidos afrancesados com véus mais curtos e sem grandes detalhes. Nas décadas de 1940 e 1950 os vestidos retornam aos modelos mais longos e, finalmente, em 1960 a minissaia chega ao casamento. O ritual sagrado do matrimônio não escapa à ousadia das mulheres que se atrevem a profanar o vestido de noiva, um dos principais símbolos da união conjugal. Apesar de continuarem sendo entregues pelos pais aos maridos, numa espécie de transferência de responsabilidades entre os homens, as mulheres sutilmente imprimem a sua marca no registro das imagens nupciais.

No álbum, as páginas seguintes mostram mulheres sozinhas que se olham no espelho, fotografadas entre flores, sentadas ao lado de presentes que, em sua maioria, confirmam seu reinado doméstico. Entre batedeiras, liquidificadores, ventiladores, copos e panelas, a mulher reina absoluta. Afinal, o único dote que agora carrega é o de mulher prendada. ${ }^{3}$

Pelo acervo coletado, percebemos que a foto com os presentes ganhos começou a aparecer na década de 1960 e praticamente desapareceu na década de 1990. Entretanto, a solidão da mulher em muitas páginas do álbum chega a sugerir que aquele dia é uma satisfação quase individual. O buquê é desesperadamente disputado por aquelas que esperam chegar seu dia. E em outra foto 
aparece repudiado por homens que correm na direção contrária ao "mau presságio". Em seu estudo sobre o amor burguês, Peter Gay sugere que o ideal romântico implicava uma nova avaliação da natureza feminina e do lugar da mulher. Para exemplificar a argumentação, cita os versos famosos de Byron em Don Juan: "o amor, para o homem, é distinto de sua vida, e é toda a existência da mulher". Prosseguindo com sua inferência, Gay acrescenta que para o ideal de amor burguês "o homem se situa no mundo feio e impiedoso dos negócios e da política ... A mulher, por sua vez, guardiã do lar e da pureza familiar, tem o tempo e o dever, nada menos que a missão sagrada, de pôr o amor em primeiro lugar" (Gay, 1990, p.55). Por mais que as mulheres tenham assumido outros lugares e funções na vida pública e no cotidiano do casamento, as fotos da união conjugal reproduzem imagens de permanência na definição dos papéis masculino e feminino ao longo de um século de fotografias nupciais.

A partir da década de 1980, todo tipo de matrimônio parece ser digno de registro. A noiva continua de branco, mas a seu lado o noivo acaricia a barriga que já tem sexo e nome. Em outra, um senhor de 71 anos segura firmemente a mão de sua recém-esposa de 17 anos. Uma mesma noiva aparece algumas vezes no painel que nós montamos, entretanto, não se trata do mesmo casamento, nem do mesmo marido.

Entre rupturas e permanências, as fotografias de casamento indicam que em mais de cem anos de amor fotografado, o casal continua organizando suas imagens matrimoniais à espera do "felizes para sempre". ${ }^{4}$

\section{O AMOR E A PAREDE (OU O RETRATO PINTADO)}

Uma das fotos que nos chegou registra, pelo clique da câmera digital, as bodas de ouro de D. Raimunda e Seu Antônio. Atrás do bolo que indica 50 anos de união, os dois fazem pose desajeitada e sem intimidade com a coisa que os mira naquele instante. Emprestada por D. Raimunda, a foto tamanho “14 x 17" foi exposta em meio às outras, no painel da exposição. A iluminação da foto não é das melhores e o casal não teve muito tempo para caprichar na pose. Mas esse não é o único momento de D. Raimunda e Seu Antônio na exposição.

Bem no centro da parede dedicada aos retratos pintados, o casal aparece em destaque numa pomposa moldura ovalada. D. Raimunda tem seus cabelos 
muito bem arrumados, usa brincos de ouro e vestido de cetim, enquanto Seu Antônio aparece a seu lado com paletó garboso e olhar altivo. A pele negra aparece ligeiramente nuançada no tom claro proposto no retrato. Pelas mãos de um pintor, o jovem casal foi apresentado com ares nobres em tamanho e matizes honrosas. Assim, os dois foram compor o centro do módulo que destaca o retrato pintado como uma "inusitada" coisa do amor.

Quando iniciamos a campanha de coleta dos objetos, fomos surpreendidos algumas vezes, pois as pessoas selecionavam objetos que nosso olhar ansioso pouco entendia como românticos. O retrato pintado foi um desses que nos convenceram de sua história de amor.

No interior do Estado do Ceará, é comum encontrar, na parede da sala ou do quarto, o retrato pintado do casal. Algumas vezes, as pinturas na parede tratam de apresentar não só o homem e a mulher, mas todo o resto da família que, em volta do casal, concretiza a realização daquela união conjugal, qual seja, a prole toda vestida em cetim de várias cores e rostos róseos rodeados por nuvens. Nessas molduras, homens e mulheres têm suas imagens recriadas pelas tintas do pintor que incorpora atributos e valores ao casal freguês. Ali o mundo real ganha os tons do desejo e da união que ficará na parede por muito tempo (até que alguém invente uma exposição desse tipo).

Os retratos emprestados para a exposição saíram direto da parede para o Museu. A poeira na moldura demonstrava que, depois de afixadas, aquelas imagens poucas vezes foram deslocadas de seus lugares. É possível até imaginar a marca que a ausência da moldura pintou na parede.

E assim aconteceu. Dois meses depois de aberta a exposição, começaram a chegar os primeiros murmúrios de saudade. A parede reclamava a ausência do quadro e as viúvas partilhavam com ela o vazio deixado. Dona Raimunda foi a primeira a apelar para o retorno de seu querido Antônio. Era através do retrato pintado, exposto no centro de sua sala, que o marido ausente se aproximava dela todos os dias. Os retratos ganharam um significado ainda maior, pois entendemos por que o retrato pintado foi o objeto que encontrou maior resistência ao empréstimo. Em nome do amor, devolvemos todos os quadros e, para resolver o problema expográfico, fizemos cópia colorida dos retratos pintados.

E foi assim que D. Raimunda e Seu Antônio, D. Socorro e Seu Izidoro, D. Neuza e Seu José, D. Neuma e Seu Francisco, D. Maria Luiza e Seu José Lima, 
D. Maria e Seu Carlos, D. Nemésia e Seu João, D. Maria Luiza e Seu João Ramos saíram de suas paredes para o Museu. Deram um rápido passeio, mas não puderam se demorar pois as coisas do amor só existem acompanhadas de memórias que nem sempre querem ser História.

\section{O AMOR ENTRE LINHAS}

Pacoti, 16 de abril de 1921.

Querida Alayde...

Como vejo-me bem correspondido venho por meio desta para saber si queres casar com migo, espero resposta urgente.

Sem mais,

Do que te consagra verdadeiro amor

José Lopes da Silva

Pacoti, 18 de abril de 1921.

Ilmo Sr. José Lopes,

Mil saudades!

Recebi vossa cartinha. Induz-me a grande amizade que te dedico e um sagrado dever a respondel-a.

Em resposta dou vos um - SIM.

Crê-me sempre fiel.

A que muito te ama

Alayde.

O amor de Alayde e José Lopes foi registrado em folhas que puderam ser lidas pelos visitantes do Museu do Ceará. Bastou abrir a caixa que nos foi entregue e começamos a entender o que chamaríamos de "amor por escrito". Muitas outras cartinhas e bilhetes chegaram até nós, mas entendemos que o fato de estar escrito não significava que aqueles objetos caberiam no módulo da escrita do amor. Concluímos que as cartas de Alayde e José Lopes não eram apenas mais um recurso romântico, senão a própria marca daquela união. $\mathrm{O}$ capricho na escolha do papel, o preciosismo com as palavras, a caligrafia perfeita. Aquela história não era tão comum nas primeiras décadas do século XX 
no Ceará. Poucos tinham acesso à escola e à escritura do amor, privilégio raro por aqui.

O amor de José Lopes e Alayde foi sendo cultivado com tinta, papel e muitos adjetivos. Antes de dizer do seu amor no altar da Igreja de Santa Rita, em Redenção, Alayde traçou as três letras com esmero em um papel igualmente bem cuidado. O S enlaçou o I que se enroscou no $\mathrm{M}$, de modo alegórico e intenso. Por cima da pequenina palavra, Alayde circulou a caneta diversas vezes para que de longe o noivo pudesse ler suas intenções. E foi assim que José Lopes ficou sabendo da resposta de sua amada. Tão logo abriu o envelope, enxergou o SIM, e, durante alguns anos, os dois escreveram centenas de linhas um ao outro.

A intensidade do compromisso era medida pela quantidade de envelopes, bilhetes, cartões, poemas e livros acumulados na gaveta. Ao passo que sentiam o amor crescer, Alayde e José Lopes melhoravam os tinteiros, renovavam as canetas, sofisticavam os papéis, ampliavam os textos, enfeitavam as letras e aumentavam as assinaturas. Até mesmo as flores que se remetiam já vinham amassadas pelo peso das páginas de algum livro.

Resolvemos destacar esta história de amor. Justamente ela poderia ser lida brevemente pelos visitantes. Ao contrário dos demais casais, os perfis de José Lopes e Alayde não aparecem por meio de fotografias, mas pela ênfase nas suas assinaturas. Os nomes ganharam destaque na parede acima dos expositores com suas cartas. A imagem do casal é construída entre linhas e tinteiros. Ao lado, uma escrivaninha tenta criar a relação da mobília com o universo da escrita.

O núcleo do módulo foi delineado pelo amor de Alayde e José Lopes, conduzido como peça de uma memória guardada entre palavras escritas. Engavetado entre agulhas de crochê e amostras de bordado. Pelo traçado das letras, o enlace assumiu os contornos do romantismo literário e, por isso, cabe em seus textos, espaço para a palavra amor. O amor romântico, endossado sobremaneira pela literatura dos séculos XVIII e XIX, prescreve o afeto como elemento indispensável para o enlace matrimonial. Diferente do chefe da segunda seção, que esqueceu de assinar sua carta, Alayde e José Lopes escreviam AMOR entendendo que nesses tempos o lugar do amor era antes de tudo o da razão escrita. Sua história romântica não tinha a crueza das palavras ditas. Quem sabe até, poucas vezes tenham falado do seu (des)amor um ao outro. 
O AMOR (IN)VERSO

Na literatura de cordel encontra-se uma infinidade de títulos que abordam histórias de amor contadas das formas mais diversas. Os cordéis mais antigos constroem enredos ao sabor dos romances de cavalaria medievais. Grandes batalhas para conseguir o amor da donzela pretendida; lutas contra dragões e monstros; uma multiplicação de pequenos episódios para temperar a trama que conta a história de Juvenal e Leopoldina, Artuzinho e Julieta, Alonso e Marina... Como argumenta Martine Kunz, esses poetas procuram histórias contestadoras nos mais diversos temas, inclusive no amor. Desse modo, escreve a autora: "os grandes amantes românticos, Artuzinho e Julieta, Alonso e Marina ... amam-se contra todos e contra tudo. $\mathrm{O}$ amor contestador da ordem adversa confunde-se com a procura da liberdade e da dignidade" (Kunz, 2001, p.63).

Algumas dessas histórias são reeditadas até hoje e, em geral, o que sofre maior alteração é o formato da capa, seguindo a estética do amor em voga no momento da publicação. Por exemplo, as capas dos anos 1930 e 1940 foram elaboradas em xilogravura, ou em foto preto e branco retirada de cenas românticas do cinema mudo. Nas décadas de 1950, 1960 e 1970 as capas ganharam as cores e a plástica dos cartazes e propagandas de filmes hollywoodianos, assim como o conteúdo dos versos, algumas vezes, também seguiu a linguagem dos romances cinematográficos.

O Museu do Ceará possui um acervo significativo de títulos e autores de cordel. A presença dos cordéis inseriu na exposição uma leitura mais desobediente e fora de ordem, a respeito do amor. Além dos romances cavalheirescos, outros contam histórias de assassinatos, traição, zoofilia, ciúmes e mistérios sobrenaturais em face do amor e da paixão. São histórias lidas e/ou conhecidas em diferentes cantos do estado do Ceará. Expusemos quase sessenta títulos que traduzem a leitura de vários poetas desde a década de 1940, no Ceará. Trata-se de uma escritura oral ou de uma oralidade escriturada acerca do namoro, do casamento e do amor in(verso).

\section{O AMOR DEVOTO}

Começaram a surgir inúmeras histórias de união patrocinadas pelas mais diferentes e espantosas simpatias. Café coado na calcinha, histórias de rezas 
com água na bacia, facas enfiadas na bananeira, espelhos observados à meia-noite eram algumas das práticas encantatórias largamente utilizadas no Ceará. ${ }^{5}$ Mas atenção: de todos os encantamentos, o mais recomendável e eficaz era a tortura a Santo Antônio. O santo é enforcado, surrado, degolado, pendurado de ponta-cabeça, untado com pimentas vermelhas e afogado. Os rituais pagãos misturam-se à devoção do santo católico na busca de um marido. Afinal, essas pequenas intervenções mágicas são coisas de bruxa, e não de homem. Muitas mulheres do meio rural ou mesmo da cidade acreditam enlaçar maridos pelo uso da simpatia, apesar da reprovação dos padres paroquianos e pastores protestantes. ${ }^{6}$

Compusemos o módulo com um expositor na forma de um grande oratório popular, expondo as diversas versões de tortura ao santo, muitas delas acompanhadas de velas de vários tamanhos. Ao lado, uma quadrinha na forma de prece implora ao santo que resolva a condição de vitalina. ${ }^{7}$

Ai, ai, Santo Antônio tenha dó/ Já estou ficando velha/ Já estou ficando só Eu vivo só/ E sem ninguém/ E quem eu quero/ Não me quer bem

Eu quero um moço/ Rico e formoso/ Não peço mais/ Porque sei qu'isto é custoso

\section{O AMOR E O MERCADO}

Uma enxurrada de bichinhos, caixinhas e biscuits foram emprestados para a exposição. Contudo, não encontramos uma boa resolução estética na mostra de todos os objetos. Assim, decidimos escolher apenas um, aquele que mais se repetia nas vitrines da cidade. Desse modo, um expositor na forma de vitrine abrigou um meigo e inofensivo ursinho branco que segurava apaixonadamente entre seus braços um coração vermelho bordado com a frase I love you.

Como não poderia deixar de ser, uma infinidade de objetos eróticos foi garimpada pelos alunos em sex shops da cidade. Sabíamos que uma exposição sobre o amor não poderia se furtar à dimensão erótica. Contudo, eram objetos polêmicos, e tínhamos dúvidas sobre a melhor forma de expor o erotismo amoroso. Concluímos que aquele tipo de erotismo não era para ser exposto, pois participava de uma faceta amorosa totalmente privada. Aqueles objetos normalmente são mostrados em vitrines ambientadas para o comércio do sexo. 
Quando saem daquele espaço público, entram na mais profunda intimidade dos amantes.

Depois de dias pensando em como solucionar o problema dos objetos eróticos, encontramos a saída, ironicamente, numa porta fechada. O que pode aguçar mais a curiosidade de um indivíduo do que uma porta fechada com uma fechadura em destaque? Motivados pela luz que sutilmente saía da fechadura, os visitantes não hesitavam em dar uma olhadinha. Mas, atrás da porta os olheiros ansiosos só enxergavam a seguinte frase: "o que se passa na cama é segredo de quem ama” (Carlos Drummond de Andrade).

Antes de sair, os visitantes tinham à sua disposição uma parede inteira, na qual podiam deixar recados, declarações de amor, corações, desabafos e o que mais quisessem grafar para expressar a ideia de que toda essa exposição não foi senão "coisa do amor".

\section{CONSIDERAÇÕES FINAIS}

O dia da abertura da exposição reuniu professores, alunos, familiares e amigos. Todos se viam na exposição em fotos, objetos, cartas, caixinhas, simpatias... Faziam parte da História, essa era a primeira grande novidade provocada pela exposição. Ali não havia objetos com nomes e sobrenomes já conhecidos na história do Ceará. O tema do amor abria a possibilidade de inserir a história dos alunos como uma questão historiográfica. E mais do que isso, criar um sentimento de pertença efetiva nos caminhos e tempos da cidade. A satisfação dos alunos, seus pais, avós, tios e primos dava-nos a certeza de construir, naquele momento, a façanha mais cobiçada pelo ensino de história: o entendimento de que todos somos sujeitos da História.

Ali, juntos estávamos em nome do sentimento que, afinal, ajuda a compreender o homem na sua existência, seja por sua presença ou por sua falta. Os alunos do curso começaram, portanto, a construir o desvio necessário no pensar historiográfico. Iniciaram a aventura de tirar a História da linha e colocá-la no fluxo temporal menos organizado, com direito a sonhos, desejos e delírios, entre outros temas rejeitados por uma historiografia e uma didática instituídas desde o século XIX. Além disso, fizemos valer a aproximação entre universidade, escola e comunidade. 


\section{REFERÊNCIAS}

ARIĖS, Philippe. O amor no casamento. In: ARIÈS, Philippe; BEJIN, André (Org.) Sexualidades ocidentais. São Paulo: Brasiliense, 1982.

BAKHTIN, Mikhail. A cultura popular na Idade Média e no Renascimento: o contexto de François Rabelais. São Paulo: Hucitec; Brasília: Ed. UnB, 1993.

BERGSON, Henri. Matéria e memória: ensaio sobre a relação do corpo com o espírito. São Paulo: Martins Fontes, 1990.

BIANCO, Bela Feldman; LEITE, Miriam Moreira. Desafios da imagem: fotografia, iconografia e vídeo nas ciências sociais. Campinas, SP: Papirus, 1998.

FABRIS, Annateresa (Org.) Fotografia: usos e funções no século XIX. São Paulo: Edusp, 1998.

FOUCAULT, Michel. História da sexualidade: o cuidado de si. 4.ed. Rio de Janeiro: Graal, 1985.

GAY, Peter. A paixão terna: a experiência burguesa, da Rainha Vitória a Freud. São Paulo: Companhia das Letras, 1990.

KUNZ, Martine. Cordel: a voz do verso. Fortaleza: Museu do Ceará; Secretaria da Cultura e Desporto do Ceará, 2001.

LEITE, Miriam Moreira. O retrato de casamento. In: Retratos de família: leitura da fotografia histórica. São Paulo: Edusp, 2000.

ONG, Walter. Oralidade e cultura escrita: a tecnologização da palavra. Campinas, SP: Papirus, 1998.

THOMAS, Keith. Religião e o declínio da magia: crenças populares na Inglaterra dos séculos XVI e XVII. São Paulo: Companhia das Letras, 1991.

\section{NOTAS}

${ }^{1}$ Michel Foucault, em seus estudos sobre o vínculo conjugal, argumenta que outrora o casamento se dava antes de tudo pela junção de funções de complementaridade entre o homem e a mulher: "a vida conjugal se caracterizava por uma repartição dos encargos e dos comportamentos na forma da complementaridade; o homem tinha que fazer aquilo que a mulher não podia realizar, e ela, por sua vez, efetuava as tarefas que não eram do âmbito de seu marido; era a identidade do objetivo (a prosperidade da casa) que dava unidade a essas atividades e a modos de vida, por definição, diferentes" (FOUCAULT, 1985, p.161).

${ }^{2}$ Como infere Miriam Moreira Leite, o retrato é o último ato de publicidade da união, que já foi testemunhada pelos que viram os proclamas, os convites ou participações e acompanharam o cortejo nupcial. Como os brindes, o banquete, o vestuário, a decoração e todo o 
consumo e ostentação de riqueza, o retrato, por sua qualidade e quantidade, pretende estabelecer o prestígio social do casa, ou das famílias de que proveio (LEITE, 2000, p.112).

${ }^{3}$ Conforme Philippe Ariès "o casamento era um tratado que empenhava a palavra dos contratantes entre duas famílias. Uma dava uma mulher, a outra família a recebia em troca de um dote" (ARIÈS, 1982, p.165).

${ }^{4} \mathrm{~A}$ indissolubilidade foi reforçada como princípio matrimonial quando o casamento assumiu a natureza de sacramento da Igreja, quando esta procurava obter um maior controle sobre a vida dos cônjuges. Não encontrou grande resistência pois o stabilitas aliou-se rapidamente a um outro valor das comunidades rurais que se referia à impossibilidade de voltar atrás com a palavra dada. Talvez seja possível dizer que somente por volta do século XIV o "felizes para sempre" passa a ser desesperadamente buscado pelos casais. Tudo indica que é também nesse momento que ele é incorporado como valor moral nos contos de fada. Sobre o tema ver ARIÈS, 1982, p.75.

${ }^{5}$ No Ceará, as festas juninas que celebram a colheita do milho fazem parte do calendário cristão e comemoram a devoção a três santos: Antônio, Pedro e João. Aproveita-se a ocasião para, em nome da fé nos santos, realizar simpatias para arranjar namorado ou marido.

${ }^{6}$ A reprovação da magia por parte da Igreja se deu com mais ênfase depois da Reforma Protestante. Até então, a Igreja medieval atribuía aos padres e santos poderes mágicos semelhantes aos curandeiros e magos do mundo pagão. As imagens dos santos eram utilizadas como amuletos mágicos. Essa faceta da Igreja medieval aproximava seus pregadores dos saberes populares. Mesmo depois que a Igreja passou a perseguir os praticantes de magia, esses rituais continuaram a ser exercitados na clandestinidade, e jamais foram abolidos do universo de crenças populares. Sobre o assunto ver: THOMAS, 1991; BAKHTIN, 1993.

${ }^{7}$ No interior do Ceará, recebem a alcunha de vitalina aquelas moças que já têm mais de 23 anos e ainda não casaram.

Artigo recebido em 24 de setembro de 2014. Aprovado em 23 de outubro de 2014. 